\title{
Acumulación y control en el circuito productivo de la vid en San Juan, Argentina
}

\author{
The Accumulation and Control in the Grape Vine Productive \\ Circle in San Juan, Argentina
}

Acumulação e Controle no Circuito Produtivo da vid em San Juan, Argentina

\author{
Delia De la Torre* \\ Margarita Moscheni ${ }^{\star \star}$
}

Recibido: 8 de julio de 2014

Aprobado: 1 de diciembre de 2014

Doi: dx.doi.org/10.12804/territ32.2015.06

Para citar este artículo:

De la Torre, D. \& Moscheni, M. (2015). Acumulación y control en el circuito productivo de la vid en San Juan, Argentina. Territorios, 32, 121-132. Doi: dx.doi.org/10.12804/territ32.2015.06

* Magister en Desarrollo Económico para América Latina Universidad Nacional de San Juan (UNSJ). Docente-investigadora del Instituto de Investigaciones Socioeconómicas y Departamento de Ciencias Politicas de la Universidad Nacional de San Juan, Argentina. Profesora titular del Departamento de Ciencias Politicas. Directora del Proyecto de Investigación "Estado, Economía y Sociedad en la Provincia de San Juan desde 1990 hasta la actualidad". Correo electrónico: delatorre.delia@gmail.com. ** Doctora en Ciencias Sociales. Docente-investigadora del Instituto de Investigaciones Socioeconómicas y Departamento de Ciencias Politicas de la Universidad Nacional de San Juan. Becaria posdoctoral de CONICET. Profesora adjunta de la Universidad Nacional $\Rightarrow$ 
Palabras clave

Territorio, circuito productivo, acumulación, control, subordinación.

Keywords

Territory, productive circle, accumulation, control, subordination.

Palavras-chave

Território, Circuito

Produtivo, Acumulação, Controle, Subordinação.

territarias 32

\section{RESUMEN}

El proceso de apertura y ajuste en la economía argentina de los años noventa, primero, y la posdevaluación, posteriormente, han producido una acelerada y profunda transformación en las economías regionales, en sus actividades productivas y en la recomposición estructural y funcional de sus agentes. Este trabajo tiene como objetivo principal analizar la dinámica de acumulación en el circuito productivo vitivinícola sanjuanino, entre 1990 y 2010 . La categoría central es la de circuito productivo, enmarcado en el enfoque territorial. Se describen las características de los agentes que integran el circuito, propietarios y no propietarios de los medios de producción y los rasgos que caracterizan las relaciones entre ellos para delimitar la dinámica en general del circuito productivo vitivinícola sanjuanino.

\section{ABSTRACT}

The opening and economic cutback in the Argentinean economy in the ninety decade and the posterior devaluation period have produced a fast and deep transformation in the regional economies, in the productive activities and the structural and functional composition of the social agents. This work is based on analyze the dynamic of the accumulation in the productive viticulture circuit in San Juan between 1990 and 2010. The central concept is the productive circuit as a part of territorial theory. This presentation describes the characteristics of social agents that compose the circuit, proprietors and non proprietors of the means of production and the notes that characterize the relations between them and delimit the dynamic of the grape vine economic circuit in San Juan.

\section{RESUMO}

O processo de apertura, ajuste na economia argentina dos anos noventa no primeiro lugar e a pósdesvalorização posteriormente, têm produzido uma acelerada e profunda transformação nas economias regionais, em suas atividades produtivas e na recomposição estrutural e funcional de seus agentes. Este trabalho tem como objetivo principal analisar a dinâmica de acumulação no circuito produtivo vitivinícola de San Juan, entre 1990 e 2010. A categoria central é de circuito produtivo, enquadrado no enfoque territorial. Descrevem-se as características dos agentes que integram o circuito, proprietários e não proprietários dos meios de produção, os rasgos que caracterizam as relações entre eles para delimitar a dinâmica em geral do circuito produtivo vitivinícola de San Juan. 


\section{Algunas cuestiones conceptuales ${ }^{1}$}

Se entiende por Circuito Productivo (CP) "un conjunto de unidades de producción, distribución y consumo que operan vinculadas entre sí a partir de una actividad común a todas ellas" (Rofman, 1999, p. 35$)$. Los agentes se ven diferencialmente afectados, según su inserción en los distintos eslabones de la cadena. Su posición y función determinan fuertes contradicciones que son los ejes de los procesos económicos y sociales en el territorio. "Los circuitos productivos muestran las relaciones contradictorias entre los agentes que ocupan lugares y posiciones definidas por su función en la cadena productiva, que se traducen en relaciones de dominación y subordinación” (De la Torre, 1999, p. 21), lo que se vincula por medio de relaciones técnicas y sociales. Por lo tanto, analizar todos estos elementos permite determinar el control y acumulación en el interior de los circuitos productivos. Así, el territorio tiene una especial forma de apropiación, producción y reproducción que le da su especificidad. (Marqués, 1998).

El territorio vitivinícola sanjuanino, mirado desde la teoría de los circuitos, excede la organización política-administrativa de la provincia y es considerado un circuito incompleto, ${ }^{1}$ ya que concluye en otros espacios en donde se completa la actividad de la cadena productiva.

La definición de territorio, no solo como un espacio definido por límites geográficos, sino como un ámbito de poder, de conflictos, alianzas e intereses consensua- dos o contradictorios, permite la integración de la variable política e interterritorial que requiere el estudio de los circuitos productivos.

La acumulación no es solo un concepto económico, sino que se relaciona con el desarrollo de las fuerzas productivas y con el Estado en sus distintas modalidades de intervención.

\section{Control y subordinación. El Circuito Vitivinícola Sanjuanino}

La Provincia de San Juan se ubica en el Centro-Oeste de la República Argentina. Su clima semidesértico y su territorio compartido por desierto, montaña y oasis, la distinguen de otras regiones argentinas y le imponen una especial configuración económica y social.

Históricamente, la estructuración del espacio estuvo basada fundamentalmente en las actividades agroindustriales $\mathrm{y}, \mathrm{co}^{-}$ mo eje, en la vitivinicultura. Su estructura económica tiene un peso importante en los sectores primario y secundario (con una participación de alrededor del 8,4\% y $31,9 \%$ respectivamente, según el INDEC para el 2010). El sector elaboración de alimentos y bebidas tiene una participación, dentro del sector manufacturero, de alrededor del $32 \%$.

El CP de la vitivinicultura es importante en la dinámica económica de San Juan. Más del $50 \%$ de la superficie cultivada total de la provincia está implantada con vid, siendo la segunda productora en importancia de uva para vinificar $(24 \%)$ y mostos nico:margarita.moscheni@ gmail.com.

${ }^{1}$ Para Marqués (1998) el circuito productivo es incompleto cuando algunas de las etapas de la cadena (producción, transformación, transporte, acondicionamiento, comercialización y consumo) trasciende los limites del territorio. En ese caso, los agentes que constituyen el núcleo "no están presentes en la región, y se da una efectiva traslación de excedentes desde esa región hacia otra-generalmente la región central-" (p. 31).

territarias 32

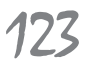


${ }^{2}$ Estos procesos fueron consecuencia tanto del cambio en el patrón competitivo mundial, como del tipo de cambio vigente y de la liberalización del comercio externo, ya que permitió la adquisición de tecnología importada.

${ }^{3}$ El núcleo de acumulación está comprendido por los grandes agentes "que lideran el cambio tecnológico y la modernización de la organización empresarial, producto de la causación circular de apropiación del excedente social de la región vía escala de producción, diversificación del producto, marcas y control de la distribución" (Gago, es Torre de la, 2003).

${ }^{4}$ Según datos del Instituto Nacional Vitivinicola, en el 2011 el 92,4\% de los viñedos en San Juan tenían menos de 25 hectáreas.

${ }^{5}$ Se diferencian de los productores de uva de mesa para exportación, porque en general realizan un proceso productivo diferencial. Es un grupo que no se puede incorporar a los llamados nuevos productores de uva de mesa que se inician aproximadamente en 1992, que culturaly productivamente se caracterizan por carecer del conocimiento y las habilidades para adaptarse tecnológicamente, no tuvieron excedentes suficien-

territarias 32 124
(48\%), luego de Mendoza, y la primera en uva en fresco $(89 \%)$ y en pasas $(94 \%)$.

A partir de 1990, presenta un fuerte proceso de reconversión basado en innovaciones tecnológicas en las fincas (riego por goteo, nuevas variedades y sistemas de conducción) y en las bodegas, secaderos, establecimientos de uvas en fresco y fábricas de mostos (procesos mecánicos e informatizados). Estas transformaciones, junto con cambios organizacionales, incidieron para que el sector se modifique cualitativamente en términos de productividad, valor agregado, nuevos mercados exportables, etc. ${ }^{2}$ (De la Torre \& Moscheni, 2013).

Este circuito se caracteriza por relaciones de dominación de los agentes que componen el núcleo de acumulación, ${ }^{3}$ una estructura trasnacionalizada y oligopsónica, y el liderazgo de espacios estratégicos en el mercado vitivinícola y el mantenimiento de vinculaciones de subordinación con los agentes medianos y pequeños. En este último grupo se encuentran los viñateros no integrados que poseen propiedades cuyo tamaño no excede las treinta hectáreas; ${ }^{4}$ los bodegueros que elaboran hasta 2 millones de vino común o mosto sulfitado; los productores de uva para pasas que producen entre 50 y $150000 \mathrm{k}$ de uva anuales y los productores de uva en fresco destinado al mercado nacional. ${ }^{5}$

Los agentes que componen el núcleo se caracterizan por ser de tamaño grande, ${ }^{6}$ con integración completa, ${ }^{7}$ uso de tecnología de última generación, captando las innovaciones con mayor rapidez y fuertes cambios en la gestión empresarial. Todo ello redunda en una importante capacidad de acumulación, derivada de altos niveles de productividad y de las relaciones de dominación que generan respecto de los otros agentes del circuito. Además, son los agentes que mayor cantidad de trabajo formalizado demandan en el circuito.

El nivel de integración completa, la actuación inter-ramas (algunos de ellos están presentes en la cadena del cartón, del olivo, entre otras) y el liderazgo en los distintos productos de la cadena de la uva (vinos básicos, premium, a granel, fraccionados, etc.), como parte de sus estrategias de acumulación, se traducen en un mayor poder y Peñaflor ${ }^{8}$ es el ejemplo más evidente de ello. "El grado de oligopolio y oligopsonio, el acceso a formas más eficientes de organización de la producción y la capacidad de obtener del poder político ciertas prebendas (financieras, económicas, legales, etc.) se agregan a los mecanismos ya mencionados" (Marqués, 1998, p.42).

Son agentes altamente competitivos, que responden a la lógica dominante del mercado internacional y que se consolidan con el modelo neoliberal, en un contexto de desregulación, liberalización, apertura, privatizaciones, flexibilización laboral y de una fuerte concentración y centralización del capital. Conforman las principales relaciones de fuerza, tanto en la provincia como en otros ámbitos en que se debaten temas estratégicos vinculados a la vitivinicultura. Son miembros titulares, directivos, presidentes y demás cargos jerárquicos en instituciones como COVIAR, Calidad San Juan, en la definición de paritarias, en 
comisiones de precios o ámbitos de diseño e implementación de políticas estatales (Instituto Nacional Vitivinícola; Instituto Nacional de Tecnología Agropecuaria; Entidad Provincial Regulador de la Energía de San Juan, ${ }^{9}$ entre otros).

Algunos de ellos son miembros de las organizaciones sectoriales (Cámaras y Federaciones) que tienen una fluida comunicación con los funcionarios y medios de comunicación.

Otros agentes del núcleo, aunque no participan de las organizaciones, pues su territorialidad $^{10}$ es tan poderosa que se imponen por otros medios, se valen principalmente de su posición privilegiada en el mercado y de la influencia directa con el gobierno de turno.

Es por medio de estos ámbitos que, coincidentemente con el discurso oficial pro vitivinícola (aunque en la realidad la vitivinicultura provincial esté perdiendo gradualmente su valor), ${ }^{11}$ definen las principales características del circuito. La formación de los precios y las condiciones de compra y venta del insumo principal (uva) y del vino son un ejemplo de ello y la institucionalización de una agricultura de contrato por medio de PROVIAR ${ }^{12}$ es otro.

En lo que respecta a los pequeños productores (menos de treinta hectáreas) se distinguen dos grupos, cuyas características definen su posición y función en el circuito. El primero, conformado por viñateros tradicionales proveedores de uva para vino común, mosto y pasas con explotaciones minifundistas que operan con reproducción simple. Esta característica se basa fun- damentalmente en el uso mayoritario de mano de obra familiar, combinada con mano de obra contratada de carácter temporal para las tareas de cosecha. Una parte de ese trabajo familiar no es retribuido y queda oculto o fetichizado bajo el precio de la uva.

Este grupo interviene en el circuito al generar una importante parte de lo producido, intercambia su mercancía en el mercado, lo que le sirve para reproducirse como fracción empobrecida del capital (posición) y como sector oferente de materia prima barata (función). Afirmar que como grupo fueron y son expoliados, implica una mirada histórica a la estructura concentrada del mercado y a un conjunto de regulaciones estatales que sostuvieron su estructural pobreza.

El segundo grupo de proveedores de materia prima está integrado por viñateros que producen uva de mesa y uva fina, cuyas explotaciones también son pequeñas pero capitalizadas. Estos agentes combinan mano de obra familiar con contratada, en un mayor porcentaje que el resto.

Tienen una organización técnica de la producción moderna, logrando ocasionalmente usar innovaciones tecnológicas, en particular en lo que se refiere a procesos, como por ejemplo el empaque bajo parral. Respecto del grupo anterior, tienen un mayor acceso al financiamiento formal, aunque en su mayoría son financiados por quienes les compran sus uvas.

En este grupo existen procesos de reproducción ampliada y tienen un nivel de excedente, aunque ceden una parte importante tes y quedan excluidos de los patrones de competitividad que se demandan al iniciar la década del noventa. Es por ello que se consideran el grupo rezagado, ya que no tienen las capacidades adecuadas para manejar los recursos hormonales, las labores en verde, fungicidase insecticidas que eviten las manchas en la uva, etc. Poseen uva cereza, criolla, moscatel y en general son multipropósito. Venden su uva a mercado interno y a intermediarios bajo la modalidad puesta en cepa. Entre las características tecnológicas se caracterizan por un marco de plantación reducido, un tipo de labranza tradicional, riego gravitacional, que tiene como consecuencia la pérdida de eficiencia en el uso del agua, un inadecuado manejo nutricional del cultivo y la ausencia de programas de prevención de plagas y enfermedades (Batistella \& Quaranta, 2010).

- Bodegas que elaboran como minimo más de 8 millones de litros de vinos, empresas concentradoras de mosto y exportadoras de uva en fresco.

${ }^{7}$ La integración se refiere a la capacidad de operar en uno o más eslabones de la cadena productiva. Si el agente interviene en un solo eslabón, se dice que no está

territarios 32

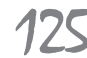


$\Leftarrow$

integrado; si opera en doso más, se denomina agente integrado. El grado de integración puede ser simple, superior-compleja y completo. La primera ocurre cuándo la vinculación se da solo entre dos eslabones, lo que significa que el agente tiene una limitada capacidad de control en el circuito. Cuando la vinculación es mayor a los dos eslabones, se denomina superior-compleja, y cuando el agente interviene en todos los eslabones es una integración completa. En este caso el agente tendrá mayor capacidad de control $y$ dominación del circuito. A mayor tamaño, habráun mayor grado de integración y el agente tendrá mayor poder y captación del excedente del circuito.

${ }^{8}$ Esta empresa lideró históricamente las relaciones productivas y comerciales en San Juan, perteneció originalmente a la familia Pulenta. En 2010 fue adquirida por Bemberg Inversora, "empresa argentina (exdueña de Cervecería Quilmes) que, actualmente, es una de las principales inversoras en el sector eléctrico argentino y desde hace unos años también incursiona en minería, por medio del control de Patagonia Gold (PGSA)" (Chazarreta, 2011, p. 12). Según su página web,

territarias 32 a los agentes de los que dependen, en general los que proveen el frío y/o aseguran la comercialización con el mercado internacional. Hay una parte del producto generado por este sector que sigue siendo hoy cuantitativamente el más importante, que se realiza como ganancia de los grupos dominantes del circuito, por medio de las exportaciones (en particular en la cadena del mosto y uva en fresco, cuya producción va destinada íntegramente a la venta internacional).

El productor de uva de mesa además está sujeto a un nivel de subordinación mayor, no solo por el nivel de concentración de los frigoríficos y comercializadores en el mercado externo - que conforman un importante oligopsonio- sino porque sus costos (y potenciales pérdidas si las hubiere) son mucho mayor que las del productor de uva común, lo que implica un nivel de dependencia significativamente alto con el operador que le asegura el mercado internacional.

Este agente debe vender a valor del dólar para asegurarse cierto margen de ganancia, ya que si el precio de mercado no es conveniente o su demanda cae no le quedará otra opción que enviar sus uvas a elaborar vino o pasas, cuyo precio es significativamente inferior a los costos de producción de la uva de mesa.

Sin embargo, más allá de las diferencias, ambos grupos (viñateros minifundistas no capitalizados y viñateros modernos capitalizados) no tienen poder de negociación y se vinculan mercantilmente con acopiadores o industriales que fijan las condiciones productivas y comerciales de la relación contractual. Ambos se enfrentan a un mercado de pocos compradores, con quienes entablan una relación de subordinación y expoliación.

De la misma manera, los agentes medianos con integración simple y superior compleja también mantienen relaciones de subordinación y dependencia con los agentes del núcleo, a la vez que repiten la misma lógica con los más pequeños.

Esta situación es similar, con algunos matices, tanto en la cadena de la uva de mesa, la pasa, como en la del mosto y el vino.

La elaboración a maquila, ${ }^{13}$ tradicionalmente usada en la cadena uva-vino, que fue originalmente creada para otorgarle mayor poder al viñatero no integrado, terminó desvirtuándose y favoreciendo al industrial. Más allá de que el bodeguero no siempre garantiza en el vino elaborado la calidad de las uvas depositadas originariamente por el productor de uva, en una relación de dependencia y asimetría es siempre quien tiene un amplio margen para imponer las condiciones de compraventa. El viñatero sin bodega tiene un bajo poder de negociación, incluso sobre el uso posterior del vino y sobretodo del precio, por lo tanto, queda rehén del bodeguero que se lo elabora.

Todos ellos son mecanismos que implican una cesión de ganancias generadas por el viñatero que queda en manos del industrial.

Respecto de las transformaciones en la relación capital-trabajo, en la década del noventa la introducción de tecnologías en 
los procesos (en particular cosecha y riego) tuvo un impacto directo en la demanda de fuerza de trabajo al reducirla. El desempleo presionó sobre las condiciones de trabajo e ingreso, lo que contribuyó a una mayor desmovilización y disciplinamiento del sector. Esta situación se modifica gradualmente a partir del 2003 como consecuencia del desarrollo de otras actividades económicas en la provincia (minería y construcción) y el surgimiento de un marco regulatorio nacional inclusivo, a partir del cual los agentes del sector trabajo se encuentran en circunstancias más favorables para reclamar mejores condiciones laborales. La Asignación Universal por Hijos, las paritarias y la firma del Convenio de Corresponsabilidad Gremial, son instrumentos al efecto.

De todos modos, la baja participación del trabajo se refuerza además por la desmovilización y debilidad de la estructura sindical. De hecho, la historia registra más cuestionamientos en la pugna por los recursos por parte de la fracción más pequeña de los propietarios del capital (viñateros) que de los trabajadores mismos.

Asimismo, si se tiene en cuenta que el $70 \%$ de los costos en la producción de uva corresponde a la mano de obra, una buena parte de la informalidad que existe facilita que sea apropiado por el capital, concretamente en lo que respecta al trabajo familiar, infantil y migrante no registrado. ${ }^{14}$ Las circunstancias son preocupantes cuando además la cosecha es una actividad comandada por cuadrilleros o ficticias cooperativas de trabajo, con prácticas inciertas, no solo en el registro de los trabajadores sino también en la garantía de sus derechos. Incluso en ese mismo tramo hay agentes que registran a sus trabajadores temporales, forzados por controles en particular del sistema impositivo, pero que no mejoran las condiciones de hábitat en donde son alojados (vivienda, higiene, alimentos, traslados, etc.). Neiman y Quaranta destacan el rol del cuadrillero como disciplinador del proceso, "la supervisión del trabajo está a cargo de la empresa, el dispositivo de disciplinamiento y de manejo de eventuales conflictos, se mantiene bajo la responsabilidad del cuadrillero" (2013, p. 88), liberando al capitalista del manejo de estos.

La renovación de contratos temporales (dan de baja y alta en condiciones ilegales), la falta de reconocimiento de viáticos, horas extras, antigüedad, categoría, la postergación de paritarias e incluso el pago de sumas no remunerativas son prácticas comunes del capital que también permiten una mayor apropiación del excedente.

Todas las estrategias antes planteadas están presentes en las distintas fracciones del capital, ya que el trabajo atraviesa cada uno de los sectores, eslabones y tamaño de agentes, aunque con distintos matices en las distintas cadenas mencionadas.

La posición ocupada por el asalariado define también la diferencia entre ingresos, respecto al promedio de lo obtenido por los trabajadores en el circuito. Estos agentes asalariados, en general profesionales, que cuentan con condiciones de mayor estabilidad y calidad laboral, tienen una mejor posición y por lo mismo logran una parte mayor de los ingresos generados en el registra ventas netas totales anuales por más de U\$S 400 millones; exportaciones anuales por 165 millones de dólares americanos, es número uno en exportaciones de vino de Argentina, conel $17 \%$ de los envios al exterior (en volumen) y posee una participación en el mercado argentino del $30 \%$ del total. Además, tiene presencia en más de 95 mercados internacionales, con marcas exitosas y reconocidas y está ubicada entre las primeras ocho productoras mundiales de vino y posee más de 6000 hectáreas propias cultivadas en diferentes climas y regiones vitivinicolas del pais.

${ }^{9}$ El gerente de la Cámara de Bodegueros participa en consejo de reducción tarifaria en el EPRE.

10 La territorialidad es definida por Mabel Manzanal citando a Lobato Correa (1994) "Conjunto de prácticas y sus expresiones materiales y simbólicas capaces de garantizar la apropiación y permanencia de un territorio dado por un determinado agente social, el Estado, los diferentes grupos sociales y las empresas" (2007, p.37).

${ }^{11}$ Según datos del INV, en el 2006 San Juan producía 7087619 quintales métricos de uvas para elaborar vinos y mostos, en el 2013 esa cifra se reduce a $6372954 \Rightarrow$

territarios 32

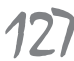


quintales. Otro dato interesante que refuerza esta afirmación es que si bien el 99,96\% del vino se vende fraccionado, dicho fraccionamiento se concentra fundamentalmente en nichos con niveles bajos, en términos de calidad, rentabilidad y precio. El multilaminado o comúnmente conocido como tetra-brik comprende el $72 \%$ de las ventas fraccionadas (en el 2000 comprendia un $74 \%)$, envases con vinos sin denominación varietal que se comercializan a precios relativamente bajos. Como consecuencia, el grueso del despacho de vinos en bodega sin mención varietal (92,4\%) fraccionados en San Juan se ubica en la franja de precios que va hasta los $\$ 4$ por litro.

${ }^{12}$ El Programa Vitivinicola Argentino se enmarca en el Plan Estratégico Vitivinicola.

${ }_{13}$ Se entiende por maquila al sistema por medio del que el viñatero, sin establecimiento industrial para elaborar sus uvas, las entrega al bodeguero, quien las procesa y obtiene el vino a cambio de una contribución previamente fijada (Moscheni \& Cherioni, 2012).

14 Neiman y Quaranta revelan que las cooperativas de trabajo elaboran estrategias en este sentido, tales $\Rightarrow$

territarias 32 128 circuito que el resto de los trabajadores, en especial los vinculados al primer eslabón.

En resumen, la generación, circulación, distribución y apropiación del excedente del circuito se encuentra determinado por los agentes que componen el núcleo. Las transformaciones territoriales más importantes a nivel mundial, referidas, los cambios en lo productivo, tecnológico $\mathrm{y}$ comercial fueron incorporadas por estos agentes y reforzadas por las regulaciones del Estado. La fase actual de globalización impulsa nuevas dinámicas de acumulación, que repercuten en el sistema económico social nacional y regional. En consecuencia, estas dinámicas que se desarrollan a nivel internacional atraviesan y afectan con magnitud variada las estructuras económico-sociales de los territorios nacionales y locales (Gago \& De la Torre, 2003).

En efecto, el escenario global, la formación y condiciones de inserción del circuito en la dinámica y regulación nacional enmarcan el circuito.

De este modo, el qué producir y el para quién producir, responde a los agentes dominantes.

La dinámica de acumulación se caracteriza por la concentración en pocas manos $\mathrm{y}$ resulta fuertemente inequitativa. Esto tiene como consecuencia una fuerte heterogeneidad en la conformación del espacio territorial y en la capacidad de los agentes del circuito en el acceso al poder. A mayor captación de excedente, mayor poder en el control del circuito, mayor acceso a los beneficios de las políticas estatales y menor riesgo productivo y comercial. Esta lógica se transforma en hegemónica, en la medida en que no es cuestionada estructuralmente por los agentes subordinados del circuito y agravada al no ser un tema de discusión en la agenda política.

Entre los agentes que componen el núcleo del circuito en la Provincia de San Juan, pueden mencionarse Peñaflor, FECOVITA, RPB, Pernod Ricard y Sallentein en la cadena del vino y mosto, a las que se le suman ENAV y MOSTOMAT para el último producto y por último EXPOFRUT y Patagonian Fruits en la cadena de uva en fresco.

En la siguiente tabla se describen las ventas, utilidades y la posición de aquellos agentes vinculados al circuito productivo vitivinícola, respecto de las 1000 empresas líderes en la Argentina para tener una dimensión de su posicionamiento no solo en la provincia sino en el contexto nacional.

Tabla 1. Ventas, utilidades y posición en el ranking de las 1000 empresas líderes de agentes vinculados al circuito vitivinícola que operan en San Juan (En pesos), 2012

\begin{tabular}{|l|r|r|r|r|}
\hline \multicolumn{1}{|c|}{ Empresa } & $\begin{array}{c}\text { Ventas } \\
\text { en \$ } \\
\text { MM }\end{array}$ & $\begin{array}{c}\text { Utilida- } \\
\text { des en } \\
\text { \$ MM }\end{array}$ & $\begin{array}{c}\text { Posición } \\
\mathbf{2 0 1 2} \\
/ 11\end{array}$ & $\begin{array}{r}\text { Q Em- } \\
\text { pleados }\end{array}$ \\
\hline $\begin{array}{l}\text { Jumbo (Junio } \\
2012 \text { ) }\end{array}$ & 14314 & 234,00 & 5 & 22500 \\
\hline $\begin{array}{l}\text { Carrefour } \\
\text { (Diciembre 2011) }\end{array}$ & 13717 & $\mathrm{~s} / \mathrm{d}$ & 7 & 18059 \\
\hline $\begin{array}{l}\text { Wall Mart } \\
\text { (Diciembre 2011) }\end{array}$ & 5126 & 72,45 & 44 & $\mathrm{~s} / \mathrm{d}$ \\
\hline $\begin{array}{l}\text { Makro } \\
\text { (Diciembre 2010) }\end{array}$ & 2788 & $\mathrm{~s} / \mathrm{d}$ & 83 & $\mathrm{~s} / \mathrm{d}$ \\
\hline
\end{tabular}

Delia De la Torre, Margarita Moscheni 


\begin{tabular}{|c|c|c|c|c|}
\hline Empresa & $\begin{array}{c}\text { Ventas } \\
\text { en \$ } \\
\text { MM }\end{array}$ & $\begin{array}{l}\text { Utilida- } \\
\text { des en } \\
\$ M M\end{array}$ & $\begin{array}{c}\text { Posición } \\
2012 \\
/ 11\end{array}$ & $\begin{array}{l}\text { Q Em- } \\
\text { pleados }\end{array}$ \\
\hline $\begin{array}{l}\text { Libertad } \\
\text { (Diciembre 2011) }\end{array}$ & 2288 & 44,84 & 108 & 4900 \\
\hline $\begin{array}{l}\text { Peñaflor (Agosto } \\
2011 \text { ) }\end{array}$ & 1379 & 55,10 & 185 & 1800 \\
\hline $\begin{array}{l}\text { Expofrut } \\
\text { (Diciembre 2011) }\end{array}$ & 697 & $\mathrm{~s} / \mathrm{d}$ & 338 & $\mathrm{~s} / \mathrm{d}$ \\
\hline $\begin{array}{l}\text { Pernod Ricard } \\
\text { (Diciembre 2011) }\end{array}$ & 650 & $\mathrm{~s} / \mathrm{d}$ & 366 & $\mathrm{~s} / \mathrm{d}$ \\
\hline $\begin{array}{l}\text { Patagonian Fruit } \\
\text { Trade (Diciembre } \\
2011 \text { ) }\end{array}$ & 321 & 4,81 & 656 & $\mathrm{~s} / \mathrm{d}$ \\
\hline $\begin{array}{l}\text { Papelera Saran- } \\
\text { dí -Leviand- } \\
{ }^{15}(\text { Abril 2010) }\end{array}$ & 154 & 13,6 & 195 & 283 \\
\hline
\end{tabular}

Fuente: Elaboración propia basada en datos "Ranking 1000 empresas líderes, 2010-2012" en Prensa económica (Buenos Aires).

La mayor cantidad de ventas está en manos de los agentes que lideran el eslabón de distribución. El poder de los retaill es de tal magnitud que trasladan hacia atrás cualquier tipo de pérdida o distorsión en sus ventas, tanto en uva como en vino o pasas. Los contratos a consignación implican que el hipermercado paga solo lo que vende, de manera que los costos negativos entre lo que el productor dejó y lo que el supermercado realmente vendió son asumidos por este. Los tiempos y formas de pago (en cheques y a largo plazo) generan utilidades para los que compran y pérdidas para los que venden, que no siempre tienen las condiciones financieras de escala y continuidad adecuadas para adaptarse.
Asimismo, Peñaflor es el agente mejor posicionado que lidera la cadena de vinos básicos, finos y mostos, teniendo activos también en la producción de cartón. Expofrut y Patagonian Fruit Trade son las exportadoras más importantes de uva en fresco, pero también lo son del resto de las frutas pepitas y de carozo. Solo Expofrut tiene entre San Juan y La Rioja 190 contratos con productores que les proveen materias primas, ya que, si bien están integrados, su extensión alcanza solo a 450 hectáreas entre las dos provincias. ${ }^{16}$ Todos pertenecen a capitales transnacionales, ${ }^{17}$ el mercado internacional comprende una parte importante de sus utilidades, aunque no todos sean extranjeros.

Los agentes exportadores más importantes se registran en la siguiente tabla:

Tabla 2. Ranking de empresas totales del país vinculadas al circuito productivo que opera en San Juan, según monto de exportaciones en MM U\$S para el 2011

\begin{tabular}{|l|c|c|c|c|}
\hline \multicolumn{1}{|c|}{ Agente } & $\begin{array}{c}\text { Total } \\
\text { MM } \\
\text { U\$S } \\
2010\end{array}$ & $\begin{array}{c}\text { Total } \\
\text { MM } \\
\text { U\$S } \\
\mathbf{2 0 1 1}\end{array}$ & $\begin{array}{c}\text { Variación } \\
\text { Por- } \\
\text { centual } \\
\mathbf{2 0 1 1 / 1 0}\end{array}$ & $\begin{array}{c}\mathbf{N}^{\circ} \text { de orden } \\
\text { en el ranking } \\
\text { de las 1000 } \\
\text { empresas } \\
\mathbf{2 0 1 1}\end{array}$ \\
\hline $\begin{array}{l}\text { Peñaflor * } \\
* * *\end{array}$ & 132 & 148 & 12,1 & 54 \\
\hline Expofrut *** & 151 & 110 & $-26,7$ & 69 \\
\hline $\begin{array}{l}\text { Patagonian } \\
\text { FT *** }\end{array}$ & 63,6 & 79,6 & 25 & 96 \\
\hline $\begin{array}{l}\text { Fecovita } \\
* * * *\end{array}$ & 34 & 56 & 64,5 & 126 \\
\hline $\begin{array}{l}\text { Salentein } \\
\text { Fruit *** }\end{array}$ & 29,9 & 22,7 & $-15,5$ & 268 \\
\hline
\end{tabular}

como fijar domicilio legalen otra jurisdicción, cambiar la razón social, contratar un seguro contra futuros juicios laborales o accidentes de trabajo y promover la inscripción de los trabajadores como monotributistas (2013, p. 90).

${ }^{15}$ Papelera Sarandi es un grupo argentino asociado con capitales extranjeros que tiene la empresa LEVIAND de uva en fresco $y$ frigorifico.

${ }^{16}$ Es una extensión poco relevante si se tiene en cuenta que en San Juan hay 9293 has implantadas para uva en fresco en el 2009 según el INV.

${ }^{17}$ Entre las 1000 empresas lideres, no hay agentes de la cadena de la pasa. Esta cadena presenta la particularidad de ser una de las menos concentradas, respecto del resto de las cadenas del CPV, además de que los lideres exportadores de pasas son de capital provincial.

territarias 32

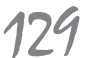


${ }^{18}$ Empresa productora y de exportación de frutas que desde 2002 tiene productores sanjuaninos de uva en fresco.

${ }^{19}$ Empresa productora de jugos, vinos, espumantes.

${ }^{20}$ Empresa concentradora de Mendoza que muele en San Juan.

${ }^{21}$ Empresa productora, empacadora y exportadora de uva en fresco. Proviene de la actividad citricola.

${ }^{22}$ Empresa elaboradora de frutas, hortalizas y verduras desecadas que en San Juan produce y exporta pasas.

${ }_{23}$ Se debe circunstancialmente a condiciones del mercado.

${ }^{24}$ Por ejemplo, la implementación de la Ley de Desarrollo Económico, en su versión de diferimientos impositivos, promovió la radicación en la provincia de agentes de capitales extra locales que invertian en el sector a cambio de diferiv el pago de sus impuestos a mediano plazo. Esta politica benefició fundamentalmente a los agentes transnacionales y grandes grupos económicos nacionales con integración completa del circuito productivo de la vid, que tenian importantes capacidades para adaptarse tecnológicamente, al modificar el perfily la composición

\section{territarios 32}

\begin{tabular}{|c|c|c|c|c|}
\hline Agente & $\begin{array}{c}\text { Total } \\
\text { MM } \\
\text { U\$S } \\
2010\end{array}$ & $\begin{array}{c}\text { Total } \\
\text { MM } \\
\text { U\$S } \\
2011\end{array}$ & $\begin{array}{c}\text { Variación } \\
\text { Por- } \\
\text { centual } \\
2011 / 10\end{array}$ & $\begin{array}{c}\mathrm{N}^{\circ} \text { de orden } \\
\text { en el ranking } \\
\text { de las } 1000 \\
\text { empresas } \\
2011\end{array}$ \\
\hline $\mathrm{ENAV}^{*}$ & 8,9 & 21,9 & 144,8 & 275 \\
\hline $\begin{array}{l}\text { Trébol } \\
\text { Pampa }^{18 * * *}\end{array}$ & 19,5 & 21,9 & 12,2 & 276 \\
\hline R.P. Baggio ${ }^{19}$ & 26 & 18,4 & -29 & 312 \\
\hline $\begin{array}{l}\text { Pernod } \\
\text { Ricard **** }\end{array}$ & 15,6 & 16,6 & 6,4 & 345 \\
\hline $\begin{array}{l}\text { Jugos } \\
\text { Australes*20 }\end{array}$ & 12,7 & 12,8 & 0,4 & 430 \\
\hline $\begin{array}{l}\text { Salentein } \\
\star * * *\end{array}$ & 9,5 & 12 & 26 & 449 \\
\hline $\begin{array}{l}\text { Argenti } \\
\text { Lemon }^{21} * *\end{array}$ & 31 & 12 & $-61,5$ & 450 \\
\hline $\begin{array}{l}\text { Viñas } \\
\operatorname{Arg}^{* * * *}\end{array}$ & 5 & 10,5 & 105 & 500 \\
\hline Mosto Mat* & 4,9 & 9,43 & 89,9 & 536 \\
\hline $\begin{array}{l}\text { Viña de } \\
\text { Montpellier* }\end{array}$ & $\mathrm{s} / \mathrm{d}$ & 8,6 & $\mathrm{~s} / \mathrm{d}$ & 567 \\
\hline $\begin{array}{l}\text { Agroexport }{ }^{22} \\
* *\end{array}$ & 6,11 & 6,3 & 4 & 708 \\
\hline Leviand* & $\mathrm{s} / \mathrm{d}$ & 5,6 & $\mathrm{~s} / \mathrm{d}$ & 784 \\
\hline
\end{tabular}

Fuente: Elaboración propia basada en datos "Ranking 1000 empresas líderes, 2011” en Prensa económica (Buenos Aires).

* Productoras y exportadoras de mosto concentrado

** Pasas

$* * *$ Uva en fresco

$* * * *$ Vinos

En 2011 Peñaflor lidera las exportaciones. Aunque no se registran entre las 1000 primeras empresas en ventas y utilidades, en el ranking de las exportaciones aparecen agentes vinculados a la cadena del mosto, como es el caso de ENAV, Viñas Argentinas y Mosto Mat, cuya producción es destinada integralmente a mercado internacional. Estos agentes mosteros tuvieron una dinámica de crecimiento significativa entre 2010 y 2011 , tal como lo indica la variación porcentual del cuadro indicada en verde. Por el contrario, los agentes líderes de la cadena en fresco tuvieron una variación negativa en el ingreso de dólares registrados por ventas externas. Incluso Expofrut, por ejemplo, registró más dólares por exportaciones en el 2001 (MM U\$S 138,03) que en el 2011 (MM USS 110,7). ${ }^{23}$

El mercado internacional y las regulaciones nacionales, ${ }^{24}$ la política monetaria, el tipo de cambio, las de comercio exterior, las impositivas e incluso el $\mathrm{PEVI}^{25}$ configuran un entramado institucional que favorece a agentes productivos que lideran la acumulación. El rol del Estado en el circuito no solo se limita a la mediación de conflictos que provoquen distorsiones en su reproducción, sino que tiene un papel principal en la creación de las condiciones necesarias de adaptación al proceso global.

\section{A modo de síntesis}

El circuito productivo de la vid que se completa en otras regiones ${ }^{26}$ y países, está articulado en torno a un núcleo de acumulación que opera territorialmente de manera transnacionalizada y oligopsónica, en la mayoría de las cadenas mencionadas.

Las empresas que lo componen tienen un fuerte avance en el control de las 
explotaciones agrícolas por medio de nuevas formas de relación con los productores o producción directa del insumo principal. Mediatizan la acción por el dominio de los eslabones de transformación y distribución. Influyen, además, en la determinación de los precios al maximizar sus niveles de rentabilidad.

Sus permanentes procesos de cambios tecnoproductivos y organizacionales, su superioridad en el manejo del mercado interno y externo, las asimetrías que imponen en su relación con los productores y su poder de negociación con los sindicatos para presionar las condiciones laborales refuerzan a estos agentes en el dominio de la acumulación regional.

El territorio vitivinícola se caracteriza además por la coexistencia de formaciones capitalistas y cuasi capitalistas y una lógica de acumulación basada en distintas estrategias de reproducción, según la posición y función del agente.

Las relaciones de producción que se manifiestan con algunos grados de flexibilización productiva con nuevas formas de relación intrafracción ${ }^{27}$ y la tendencia creciente a la flexibilización laboral y la subcontratación debilita aún más al productor independiente y lo pone en una clara situación de fuerte dependencia de las unidades líderes de transformación (control de la reconversión).

De esta manera, el circuito se sostiene y reproduce basándose en el proceso de expoliación y extracción de plusvalía. Sin estos mecanismos y sin el papel del Estado que lo refuerza, la dinámica de acumula- ción que caracteriza este circuito no sería posible. Las pocas políticas compensatorias no alcanzan a equilibrar-contrarrestar las consecuencias de este fuerte proceso de reconversión en el circuito provincial.

\section{Referencias}

Batistella, M., \& Quaranta, G. (2010). La demanda de mano de obra en uva de mesa, provincia de San Juan. En G. Neiman (Comp.), Estudio sobre la demanda de trabajo en el agro argentino (pp. 237256). Buenos Aires: Ed. CICCUS.

De la Torre, D. (1999). La Reestructuración y sus Impactos en la Agroindustria de Conserva de Tomate. El caso de la Región de Cuyo-Argentina. (Tesis de Maestría, Universidad Internacional de Andalucía, sede Santa María de la Rábida, Huelva, España).

De la Torre, D., \& Moscheni, M. (2013). Transformaciones en la vitivinicultura en la Provincia de San Juan. ¿Integración o desintegración socioproductiva? Revista Voces del Fénix, 27. Recuperado de http://www.vocesenelfenix.com/ category/ediciones/n\%C2\%BA-27.

De la Torre, D., \& Moscheni, M. (2014). Transformaciones y desafíos actuales (y no tanto) de la producción sanjuanina de los últimos años. En C. Valenzuela, A. García \& P. Rosa (Comp.), Inclusión Social en las Economías Regionales. Estrategias participativas y propuestas de articulación social en el territorio (pp. 131-138). Resistencia, Chaco: Instituto de Investigaciones Geohistóricas.
$\Leftarrow$

del capital dominante tradicionalen la provincia yal dinamizar la demanda de uva a pequeños y medianos productoressin integración. Esta norma, que se pone en marcha a partir 1990 aunque la ley fue sancionada con anterioridad a ese año-configura un modelo de desarrollo en el que se consolidan los grandes agentes vitivinicolas favorecidos con ventajas institucionales dispensadas por el Estado nacional.

${ }^{25}$ Plan Estratégico Vitivinícola Nacional.

${ }^{26}$ Un ejemplo claro de este proceso se produce en Mendoza donde una porción importante de los vinos sanjuaninos se fraccionan, con las consecuencias inevitables para la provincia de pérdida de valor agregado $y$ con el sometimiento a las condiciones que establecen los agentes del núcleo también presentes en ese espacio.

${ }^{27}$ Nuevas formas de contrato entre las empresas elaboradoras y los viñateros proveedores de materia prima. El contrato con los viñateros consiste en el otorgamiento por parte del bodeguero de los insumos (herbicidas, fertilizantes, etc.), crédito para financiar las tareas culturales y de cosecha (en algunos casos facilita la cosechadora mecánica), asistencia técnica y control $\Rightarrow$

territarios 32 
$\Leftarrow$

general de la producción en relación con las formas de cultivo, tiempos de producción; además de hacerse cargo del flete desde la finca a la fábrica. Por su parte, el productor pone el trabajo, la mano de obra y la tierra propia o arrendada y por supuesto el compromiso de venderle a la bodega. Los contratos prevén los riesgos (heladas, granizo, lluvias $u$ otros problemas) que en algunos casos se comparten. En esta forma de "cuasi integración" de las bodegas que controlan el volumen, la tecnología y la calidad del insumo, el productor pierde toda decisión sobre su propiedad. Se desdibuja de esa manera el productor independiente y es reemplazado por otro pasivo que adopta las directivas del eslabón transformación. Este tipo de contrato, es para la venta directa de la uva y especialmente para uva fina o varietal. tersitarias 32 132
Ed. UNCh-CONICET. Recuperado de http://www.ceur-conicet.gov.ar/ imagenes $/ 2$.pdf

Gago, A., \& De la Torre, D. (2003). La Región de Cuyo, situación actual y lineamientos para una propuesta de crecimiento económico con equidad. En Plan Fénix, Propuestas para el desarrollo con equidad (pp.109-119). Río Cuarto: Universidad de Río Cuarto.

Manzanal, M., Arzeno, M., \& Nussbaumer B. (Comp.) (2007). Territorios en Construcción. Actores, tramas y gobiernos: entre la cooperación y el conflicto. Buenos Aires: Ed. Ciccus.

Marqués, N. (1998). Agentes Sociales, Eslabonamientos Productivos y Diagnósticos Regionales. Buenos Aires: ILPES.

Moscheni, M., \& Cherioni, N. (2012). No todo lo que brilla es oro... la maquila y la relación de fuerzas vitivinícolas en la provincia de San Juan. En D. De la Torre (Coord.), Estado, Economía y Sociedad en la Provincia de San Juan 1950-1976. (pp. 271-278). San Juan:
Editorial de la Fundación Universidad Nacional de San Juan.

Moscheni, M. (2014). Acumulación, reproducción y conflicto. El circuito productivo de la vitivinicultura sanjuanina. (Tesis doctoral, Universidad Nacional de $\mathrm{Cu}$ yo, Mendoza).

Neiman, G., \& Quaranta, G. (2013). Eventualidad y movilización de la mano de obra en el contexto de la restructuración de la agricultura de la provincia de San Juan. Población é Sociedad, 20(1), 77-98. Recuperado de http://www.scielo.org.ar/scielo. php? script $=$ sci_arttext\&pid $=S 1852$ 85622013000100004\&lng=es\&nrm $=$ iso

Prensa económica (Buenos Aires). Ranking 1000 empresas líderes, www.prensaeconomica.com/ranking-1000-empresaslideres/

Rofman, A. (1999). Las Economías Regionales a fines del Siglo XX. Los circuitos del petróleo, del carbón y del azúcar. Buenos Aires: Ed. Ariel. 